\title{
Control of a Multi-terminal VSC-HVDC System for Wind Power Delivery
}

\author{
Mohamed Tawfik Eladl ${ }^{1}$, Yasser Gaber Dessouky ${ }^{2}$ and Ezz Eldien Zakzouk ${ }^{2}$ \\ ${ }^{1}$ Mansoura- University District, Egypt \\ ${ }^{2}$ Alexandria- Arab Academy for Science, Technology\& Maritime Transport(AAST), Egypt
}

\begin{abstract}
Among the most developed renewable energy sources, wind energy attracts the most research attentions. Wind energy is easily captured far away from the places where wind energy is used. Because of this unique characteristic of the wind, the generation and delivery systems of the wind energy need to be well controlled. This paper presents how to model and control the Multi-Terminal DC [MTDC] networks used in wind applications. The paper also provides two different control techniques, the PID controller and the Fuzzy Logic controller algorithms to ensure best power management between the wind farm side [WFS] and the grid side [GS] and to compare between the dynamic responses of the two controllers in the WFS. In the WFS, the Doubly Fed Induction Generator [DFIG] was applied as it can be directly linked to the grid and can reduce the scale of power electronics used to $30 \%[3]$ of the rated capacity hence the cost is reduced. The MTDC network with four terminals is fully simulated and tested using MATLAB/SIMULINK software.
\end{abstract}

Keywords-DFIG; fuzzy logic; HVDC; MTDC; PID; VSC

\section{INTRODUCTION}

HVDC technology is successful for long distances, high power applications or a requirement to join asynchronous $\mathrm{AC}$ networks. The main advantages of HVDC transmission system are fully controlled of power flow, less cables are required compared to $\mathrm{AC}$ transmission and transmission distance using DC not affected by cable charging currents. The converters used in MTDC are Current Source Converters [CSC] or Voltage Source Converters[VSC].The VSC technology is superior due to the following reasons[1] : simpler interface with AC systems, compact filters are used, independent control of active and reactive power, no minimum power restrictions, no commutation failures, no polarity reversal needed to reverse the power, black start capability, generation of harmonics greatly reduced so the minimization of filters used to absorb it and it has small footprint. On the other hand, there are several disadvantages of VSC such as, the cost and the complexity of stations. The commutation process has two main types self or natural commutation and forced commutation [2]. The commutation process is initiated by the reversal of AC voltage polarity. The converters which are used in simulating the MTDC system use IGBT switches (i.e. forced commutation switches). In this paper, a typical four terminals MTDC system is fully simulated using MATLAB software and the WFS is controlled using PID and Fuzzy logic controllers. The dynamic performance of the proposed control systems are compared through simulations of the MTDC system.
The GS is stable, so simple PI controller is sufficient to control the currents of the grid. This paper is organized as follows: section (II) describes the wind energy systems and the power electronics used in the MTDC system, section (III) shows the system configuration and analysis, section (IV) presents how to control the MTDC system, section (V) shows the simulation study and results based on PID and Fuzzy Logic Controllers and finally section (VI) draws the conclusion.

\section{Wind ENERGy Systems AND POWER ELECTRONICS USED}

\section{A. Wind Energy Systems (WES):}

There are several types of generators used in wind power generation[3] such as: Brushless DC (BLDC),permanent magnet synchronous generator (PMSG), squirrel cage induction generator or wound rotor induction generator(SCIG, WRIG),synchronous generators (SG) and doubly fed induction generator(DFIG).The DFIG generators are used for megawatts turbines. Some generators require a gear box system to match the speed difference between the turbine and generator such that the generator can deliver its rated power at the rated wind speed. This paper is used to model the MTDC system by using the DFIG. Any changes in the wind speed will change the power output and the DFIG will be capable to keep constant frequency with variable speed by the Rotor Side Control [RSC] and the Grid Side Control [GSC] [4, 5].

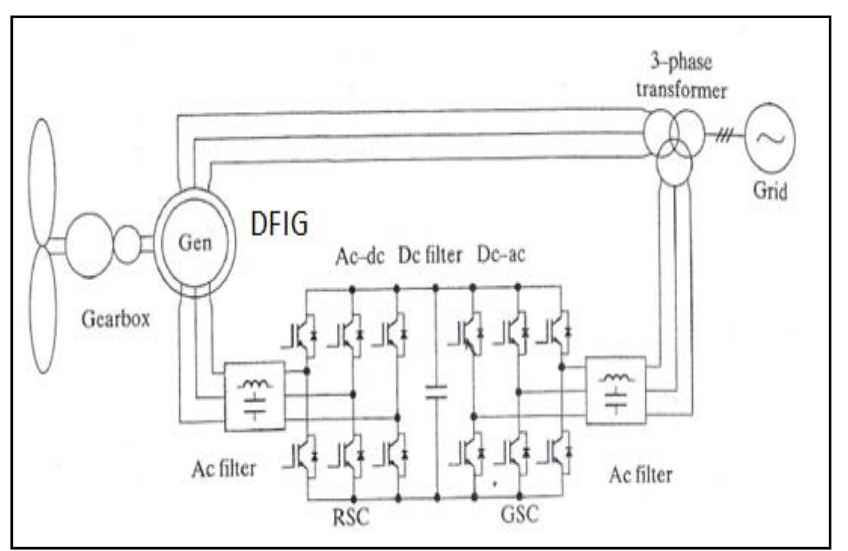

FIGURE I. THE DFIG ARCHITECTURE FOR THE WIND TURBINE 


\section{B. Power Electronics of the MTDC System:}

Multilevel Converters [6, 7] has been attracted a large interest in the power industry in the recent years. Industry has started to involve in higher power equipment, which already reaches megawatt level. Conventional power electronic converters are only able to switch each individual input or output link between two possible voltage levels, especially those of the internal DC voltage link. The general structure of the multilevel converter is to generate a sinusoidal voltage from several levels of voltages which are usually obtained from capacitor voltage sources. Three different topologies have been projected for multilevel converters: Diode clamped converter; Flying capacitor converter (Capacitor Clamped); and lastly cascaded converter. The diode clamped scheme was used in the simulations.

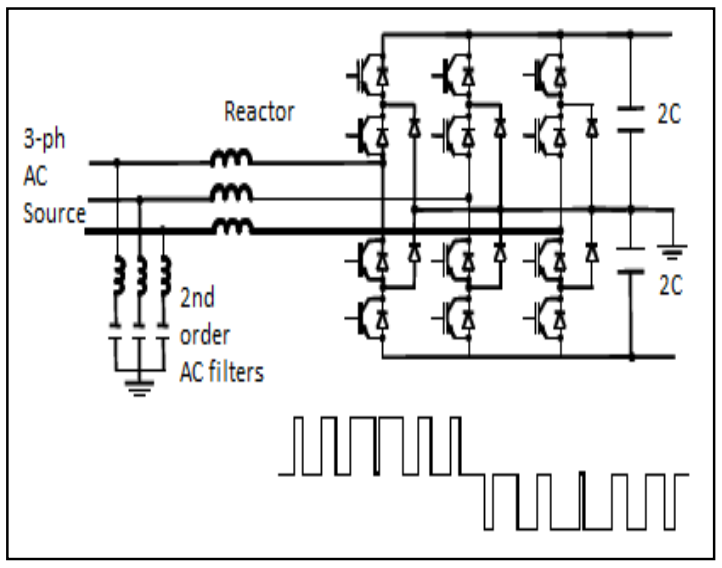

FIGURE II. VSC CIRCUIT(THREE PHASE MULTI-TERMINAL DIODE CLAMPED RECTIFIER)

\section{SySTEM CONFIGURATION AND DC GRID ANALYSIS}

\section{A. System Configuration:}

The system is divided into two sides as shown below in Figure III, the WFS and the GS. The point of common coupling [PCC] has a DC voltage of $45 \mathrm{kV}$.

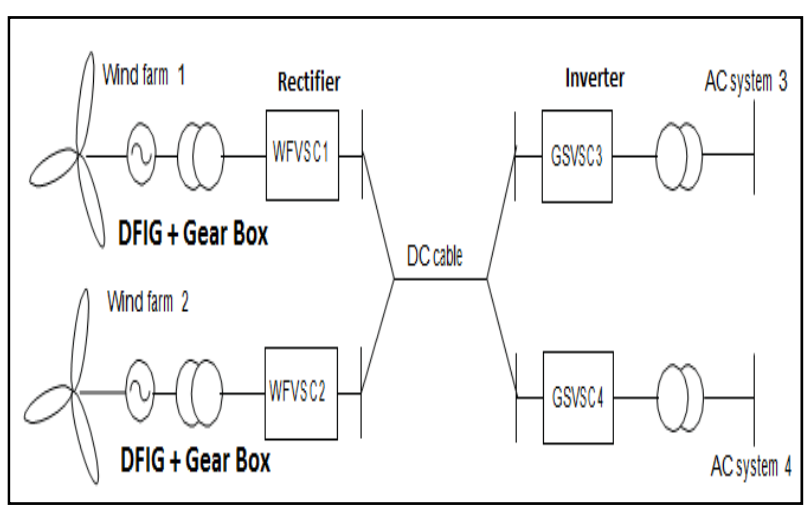

FIGURE III. SINGLE-LINE DIAGRAM OF WIND FARM INTEGRATION USING A VSC -HVDC

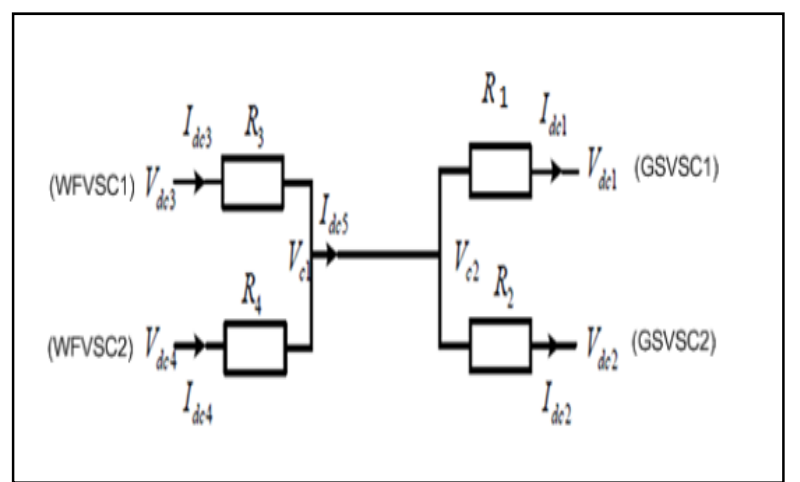

FIGURE IV. STEADY STATE EQUIVALENT CIRCUIT OF THE FOUR TERMINAL SYSTEM

\section{B. DC Grid Analysis:}

Figure IV shows a simplified steady state equivalent circuit of the four-terminal MTDC system[8,9,10] shown in Figure III where $R_{1}-R_{4}$ represents the equivalent $d c$ resistances of the five connection cables.Vdc1-Vdc4 and Idc1-Idc4 are the respective dc voltages and currents of the four VSCs.

The system equations can be summarized as follows:

$$
\begin{aligned}
& \mathrm{Vdc}_{1}=\mathrm{Vc}_{2}-\mathrm{Idc}_{1} \mathrm{R}_{1} \\
& \mathrm{Vdc}_{2}=\mathrm{Vc}_{2}-\mathrm{Idc}_{2} \mathrm{R}_{2} \\
& \mathrm{Vdc}_{3}=\mathrm{Vc}_{1}+\mathrm{Idc}_{3} \mathrm{R}_{3} \\
& \mathrm{Vdc}_{4}=\mathrm{Vc}_{1}+\mathrm{Idc}_{4} \mathrm{R}_{4}
\end{aligned}
$$

according to(1-2), the following equation can be obtained :

$$
\mathrm{Vdc}_{2}=\mathrm{Vdc}_{1}+\mathrm{Idc}_{1} \mathrm{R}_{1}-\mathrm{Idc}_{2} \mathrm{R}_{2}
$$

\section{MTDC SYSTEM CONTROL}

To perform an optimum power management to the system a PID and Fuzzy Logic control algorithms are performed. This paper presents a model of such systems also a control strategy based on PID controller and Fuzzy Logic controller. The aim of the different strategies are to ensure system reliability and proper power sharing. The target is to keep the voltages at the wind farm terminals at a constant value and to control the currents such that (Id) related to the active power and (Iq) related to the reactive power. To keep the dc voltage at a constant values, two types of controllers were used; fuzzy logic controller and PID controller, then the two responses are compared. Because of the GS is stable, so simple PI controller is so sufficient to control the currents of the grid. Here is the fuzzy logic controller membership functions and the decision table of the membership variables. The parameters of the PID controller is tuned using Ziegler-Nichols (Second Method).Figure(VIII) shows the control system applied in the WFS. 


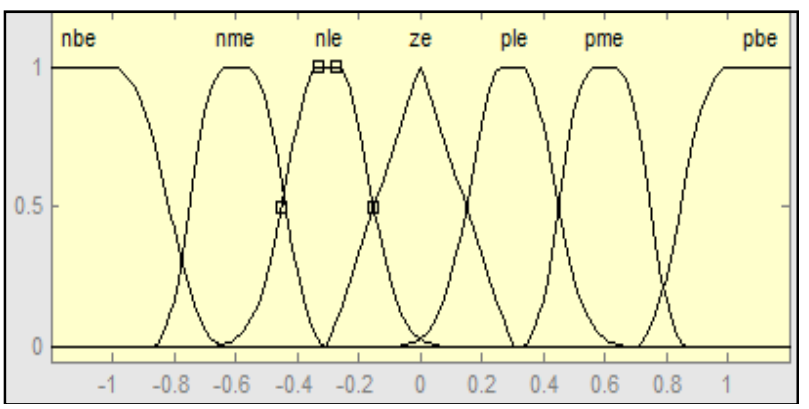

FIGURE V. THE ERROR MEMBERSHIP FUNCTIONS

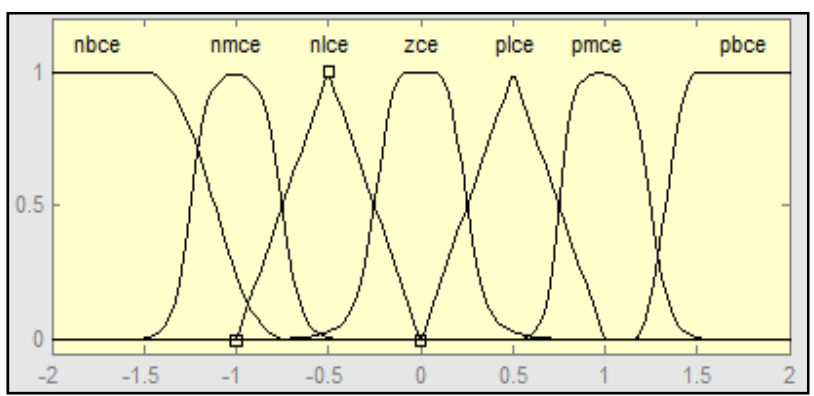

FIGURE VI. THE RATE OF ERROR MEMBERSHIP FUNCTIONS

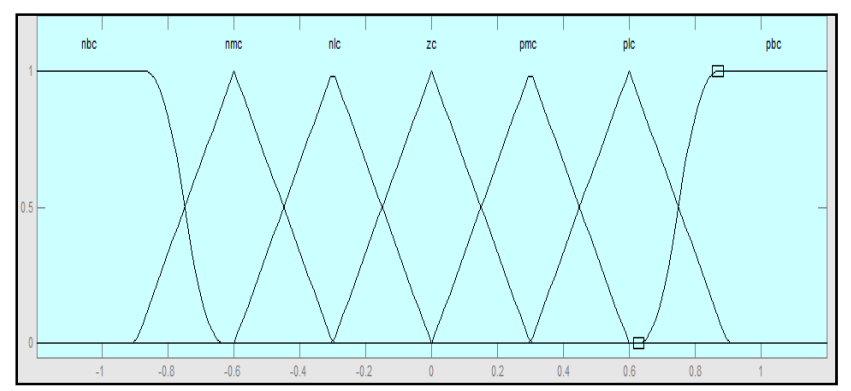

FIGURE VII. THE CONTROLLER OUTPUT MEMBERSHIP FUNCTIONS

-List of symbols:

nb: negative big

nm: negative medium

nl: negative low

z: zero

pm: positive medium

pl: positive low

pb: positive big

TABLE I. DECISION TABLE OF SEVEN MEMBERSHIP VARIABLES

\begin{tabular}{|l|l|l|l|l|l|l|l|}
\hline Error/Rate & nbce & nmce & nlce & zce & plce & pmce & pbce \\
\hline nbe & $\mathrm{zc}$ & $\mathrm{nmc}$ & $\mathrm{nlc}$ & $\mathrm{nbc}$ & $\mathrm{nlc}$ & $\mathrm{nbc}$ & $\mathrm{nbc}$ \\
\hline nme & $\mathrm{nlc}$ & $\mathrm{zc}$ & $\mathrm{zc}$ & $\mathrm{nmc}$ & $\mathrm{nlc}$ & $\mathrm{nbc}$ & $\mathrm{nbc}$ \\
\hline nle & $\mathrm{zc}$ & $\mathrm{zc}$ & $\mathrm{zc}$ & $\mathrm{nlc}$ & $\mathrm{nbc}$ & $\mathrm{nbc}$ & $\mathrm{nbc}$ \\
\hline $\mathbf{z e}$ & $\mathrm{pbc}$ & $\mathrm{pbc}$ & $\mathrm{plc}$ & $\mathrm{pmc}$ & $\mathrm{zc}$ & $\mathrm{zc}$ & $\mathrm{zc}$ \\
\hline ple & $\mathrm{zc}$ & $\mathrm{zc}$ & $\mathrm{zc}$ & $\mathrm{pmc}$ & $\mathrm{pbc}$ & $\mathrm{pbc}$ & $\mathrm{pbc}$ \\
\hline pme & $\mathrm{zc}$ & $\mathrm{zc}$ & $\mathrm{zc}$ & $\mathrm{pmc}$ & $\mathrm{pbc}$ & $\mathrm{pbc}$ & $\mathrm{pbc}$ \\
\hline pbe & $\mathrm{pbc}$ & $\mathrm{pbc}$ & $\mathrm{pmc}$ & $\mathrm{pbc}$ & $\mathrm{pmc}$ & $\mathrm{plc}$ & $\mathrm{zc}$ \\
\hline
\end{tabular}

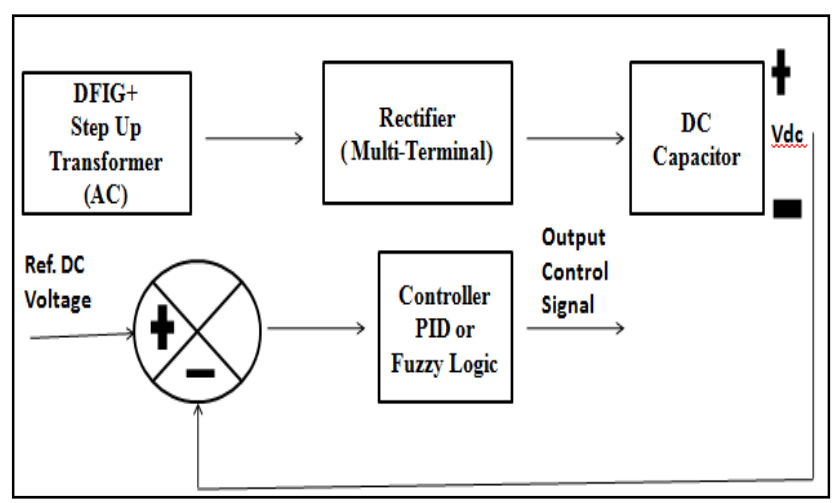

FIGURE VIII. BLOCK DIAGRAM OF THE CONTROL SYSTEM IN THE WFS

\section{SimULATION STUDY AND RESUlts BASED ON PID AND FUZZY LOGIC CONTROLLERS}

\section{A. Simulation Study:}

\section{1) The wind farm side specifications:}

As shown in Figure IX the wind farm is simulated by a DFIG, any changes in the wind speed with the help of Maximum Power Point Tracking [MPPT] module the maximum power can be extracted from the wind. The role of the DFIG rotor side converter to keep the generator working on a fixed frequency with variable speed. Then a transformer is used to step up the voltage to a suitable range to be ready for transmission. The $\mathrm{AC}$ voltage resulted from the wind farm is rectified using three phase twelve pulse multi-terminal diode clamped VSC. A capacitor is installed after the rectifier to maintain the dc voltage and smooth out the voltage waveform. The VSC is a current controlled converter so, we enter a reference value of the dc voltage (Vdc_Ref) then the controller try to reach this value. The output of this controller is a reference value of the current controller (Id _ Ref). The current is transformed from $(a b c)$ reference frame to the $(d-q)$ reference frame. Id is used for active power control and Iq is used for reactive power control. In the simulation, $\mathrm{Iq}=$ zero. Low pass filters are used to minimize the harmonics in the system with a cut off frequency of $750 \mathrm{~Hz}$. The voltage of the common point of transmission is $45 \mathrm{kV}$. Finally to control the switching between the switches, a discrete three phase PWM generator is used with carrier frequency of $3 \mathrm{kHz}$. The sampling time for the whole system is $10 \mu \mathrm{sec}$.

\section{2) The grid side specifications:}

The DC voltage which comes after the rectification and the controller effort of the wind side $(\mathrm{Vdc}=45 \mathrm{kV})$ is then transformed to an $\mathrm{AC}$ voltage by using three phase twelve pulse multi-terminal VSC (inverter). The AC voltage is then stepped down to a $22 \mathrm{kV}$ using a three phase star-delta transformer. Then the power comes from the wind farm is flowing into an $\mathrm{AC}$ grid of $11 \mathrm{kV}$. The vector control (d-q modeling) is used to provide independent control of active and reactive power of the grid side. The input of the grid side system is Id, Iq and I0 then, the controller tries to reach these commands. Iq is set to be zero (i.e. no injection of reactive power to the grid and the power factor is unity). 


\section{3) The power management scheme:}

A single case study is studied during the simulations. The wind side generates $5.5 \mathrm{MW}$ and needs to be transferred to the grid so, enter a specific current Id corresponding to the wanted power as shown below in the calculations. A step input is applied to the wind farm (2), this change in the voltage is a way to represent the change in wind speed and the power also changed so, this is a test for a controller to respond. The results show that this change in power at the wind side is transformed to the grid side and the conclusion is that the power generated by the two wind sides are equal to the power transformed to the two grid sides. The step input tests the worst case or the most severe condition that may face the wind farm. If the controllers are responding to this change, this means that all the other operating points are valid.

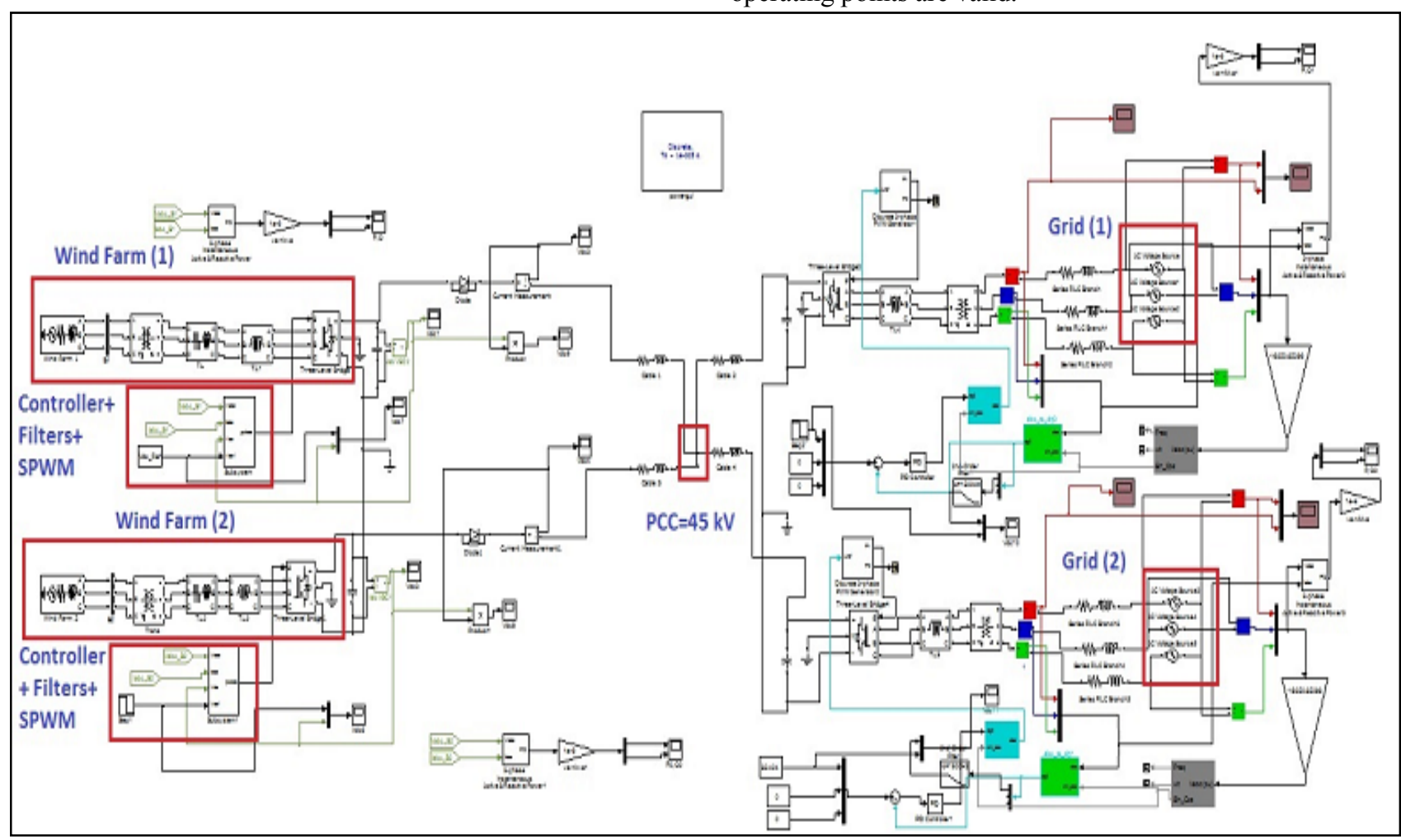

FIGURE IX. A TYPICAL FOUR-TERMINALS MTDC SYSTEM IMPLEMENTED BY MATLAB SOFTWARE.

TABLE II. POWER MANAGEMENT SCHEME BETWEEN THE WFS AND GS.

\begin{tabular}{|c|c|c|c|c|}
\hline MTDC Side & V (Volt) & I (Ampere) & $\mathrm{P}(\mathrm{MW})$ & $\begin{array}{c}\text { Total } \\
\text { Power }\end{array}$ \\
\hline WFS1 & $45800 \mathrm{~V}$ & $80 \mathrm{~A}$ & $3.664 \mathrm{MW}$ & \multirow[t]{2}{*}{$5.5 \mathrm{MW}$} \\
\hline WFS2 & $45100 \mathrm{~V}$ & $40 \mathrm{~A}$ & $1.8 \mathrm{MW}$ & \\
\hline GS1 & $6350.9 \mathrm{~V}$ & $200 \mathrm{~A}$ & $3.81054 \mathrm{MW}$ & \multirow{2}{*}{$\begin{array}{c}5.5 \\
\text { MW }\end{array}$} \\
\hline GS2 & $6350.9 \mathrm{~V}$ & $86.783 \mathrm{~A}$ & $1.65346 \mathrm{MW}$ & \\
\hline
\end{tabular}

\section{B. Simulation Results:}

\section{1) Comments on results:}

\section{a) For the GS:}

Figure $\mathrm{X}$ shows that a step input is applied to the grid 1 (Id) from $200 \mathrm{~A}$ to $86.783 \mathrm{~A}$ and the step time at 1.5 seconds. While Grid 2 the required Id equals to $86.783 \mathrm{~A}$ as shown in figure XI .Figure XII and XIII shows the phase (a) voltage and current for grid 1 and 2, it is important to notice that Va and Ia are in phase as shown in the figures, this means no reactive power is injected to the grid and the power factor is unity. Also, the Total Harmonic Distortion [THD] of the grid currents is equal to $4 \%$.

b) For the WFS:

Table III shows a comparison between the response of Vdc(1) of the WF(1) using PID controller and Fuzzy Logic controller. Figure XIV and XVI show the responses of Vdc1 using PID and Fuzzy Logic controller.

TABLE III. A COMPARISON BETWEEN THE PID AND FL RESPONSES APPLIED TO WF (1).

\begin{tabular}{|l|l|l|}
\hline System Dynamics / Controller Type & PID controller & $\begin{array}{l}\text { FL } \\
\text { controller }\end{array}$ \\
\hline Rise Time & $0.8 \mathrm{Sec}$. & $0.52 \mathrm{Sec}$. \\
\hline Settling Time & $1.1 \mathrm{Sec}$. & $0.53 \mathrm{Sec}$. \\
\hline Overshoot & $4 \%$ & $<1 \%$ \\
\hline $\mathbf{V}_{\mathrm{dc}}$ Steady State Oscillations & High & Low \\
\hline
\end{tabular}


2) The GS Results:

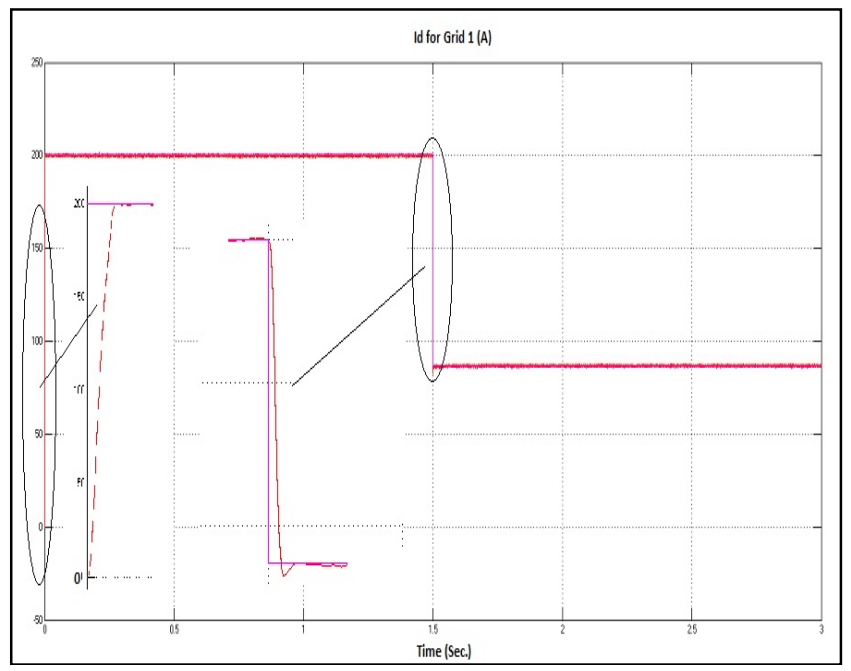

FIGURE X. Id FOR GRID 1 (A).

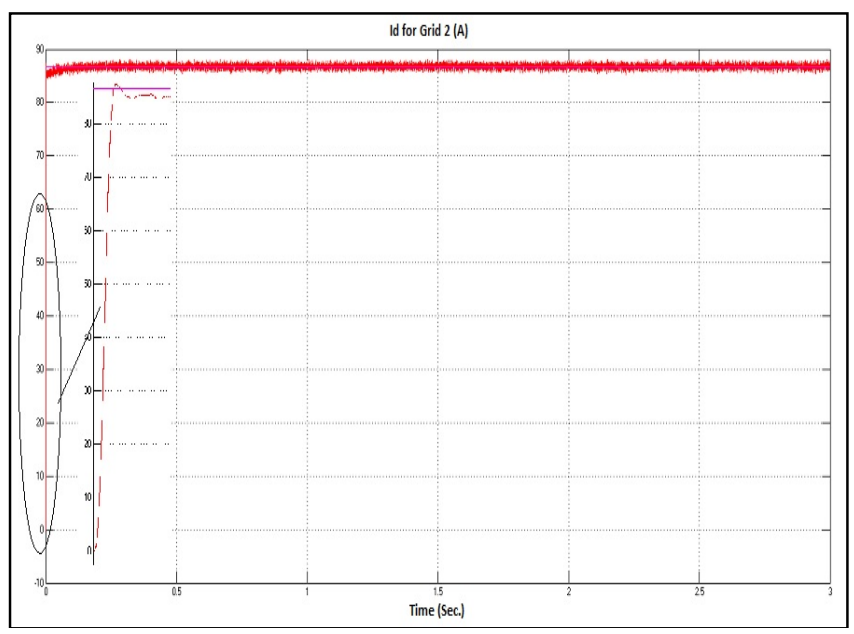

FIGURE XI. ID FOR GRID 2 (86.783A).

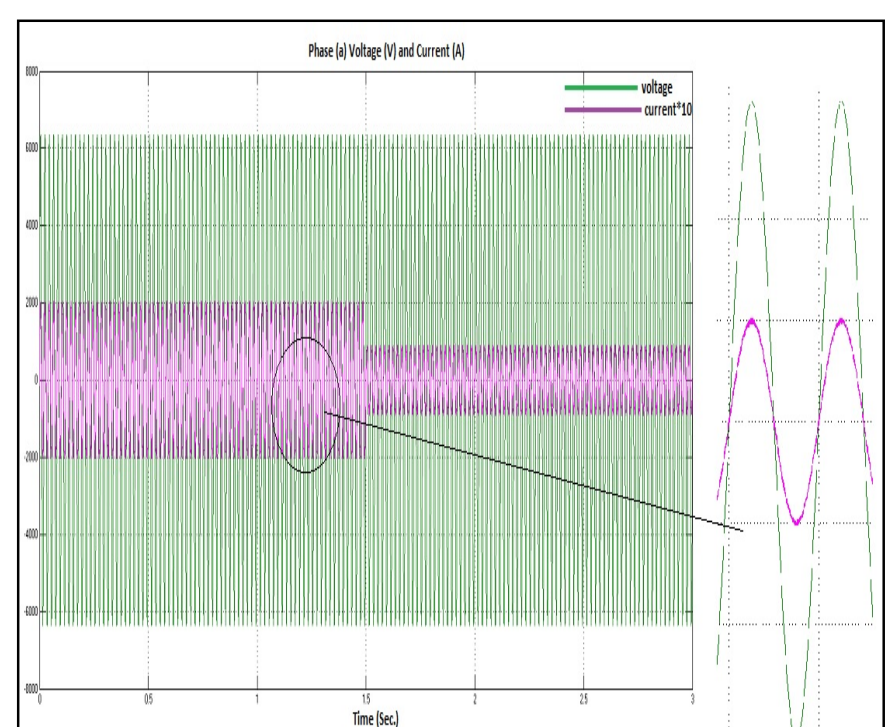

FIGURE XII. PHASE(A) VOLTAGE AND CURRENT OF GRID 1

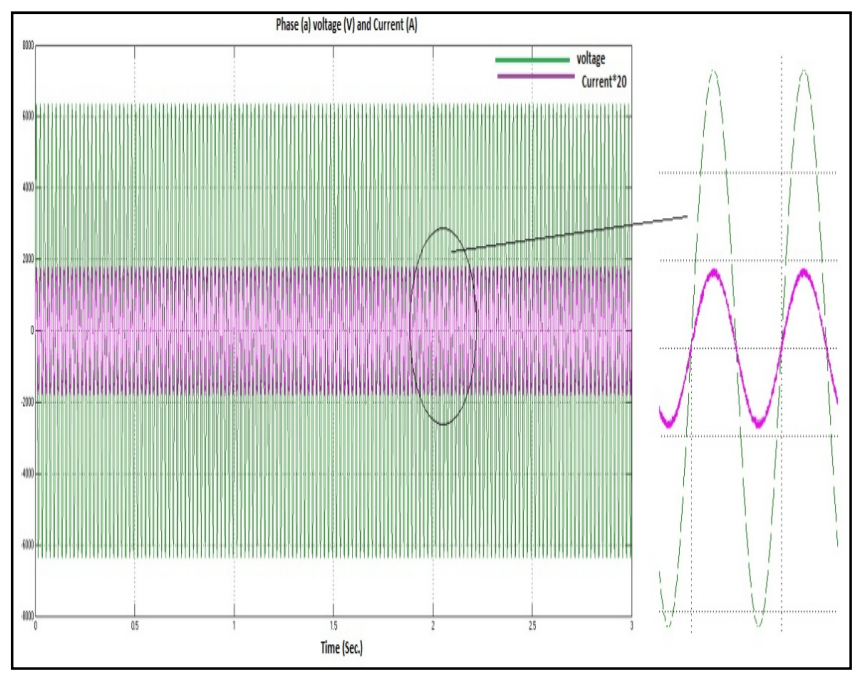

FIGURE XIII. PHASE(A) VOLTAGE AND CURRENT OF GRID 2 3) The WFS results based on PID controller:

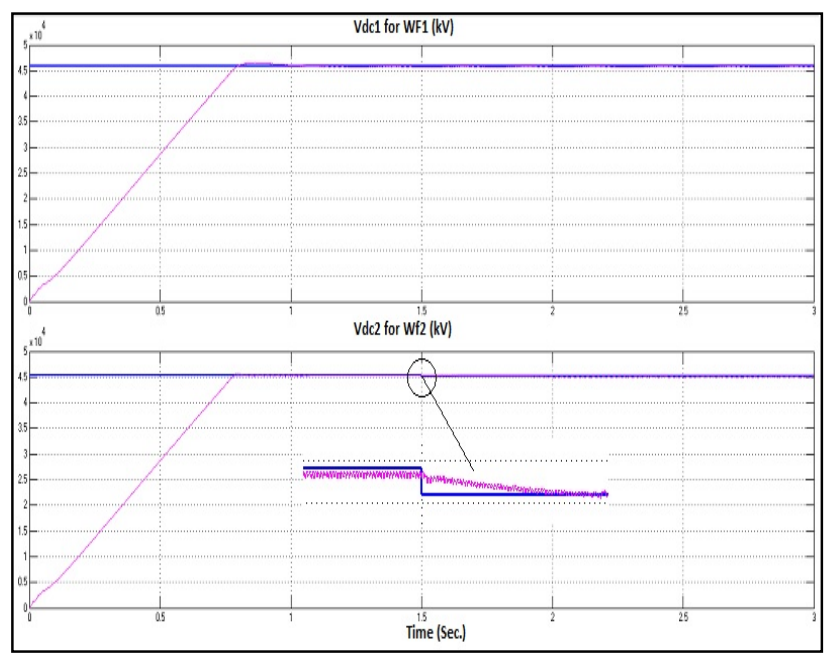

FIGURE XIV. THE DC VOLTAGE WAVEFORMS OF THE TWO WIND FARMS (KV)

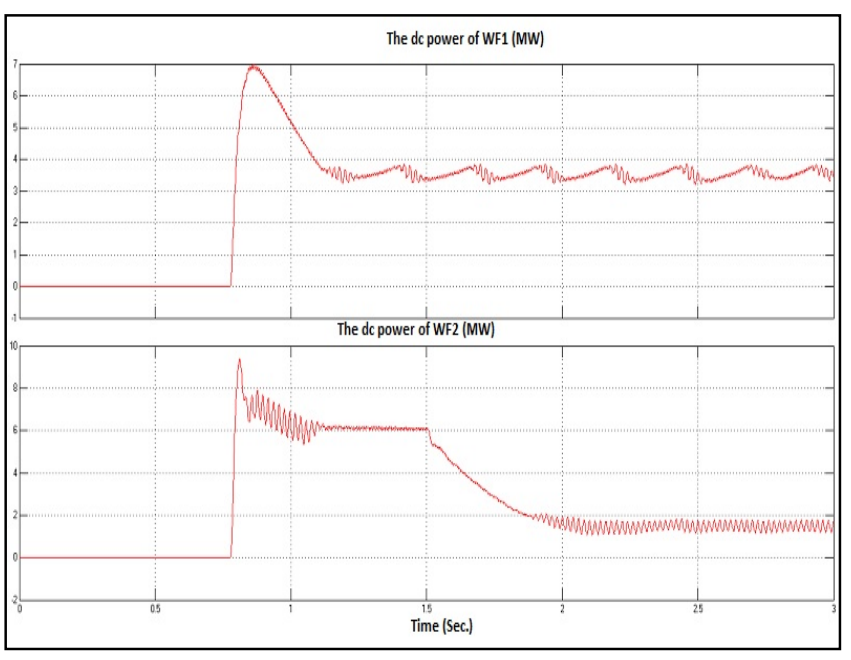

FIGURE XV. THE DC POWER WAVEFORMS OF THE TWO WINDFARMS (MW) 
4) The WFS Results Based on Fuzzy Logic Controller:

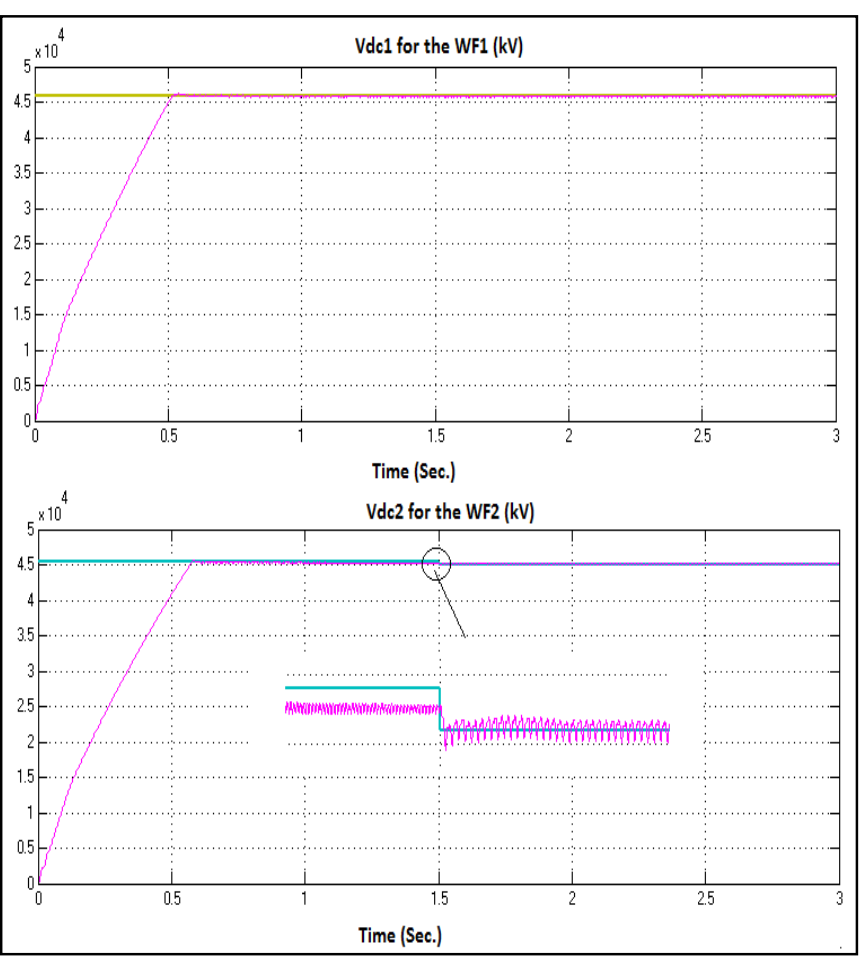

FIGURE XVI. THE DC VOLTAGE WAVEFORMS OF THE TWO WIND FARMS (KV)

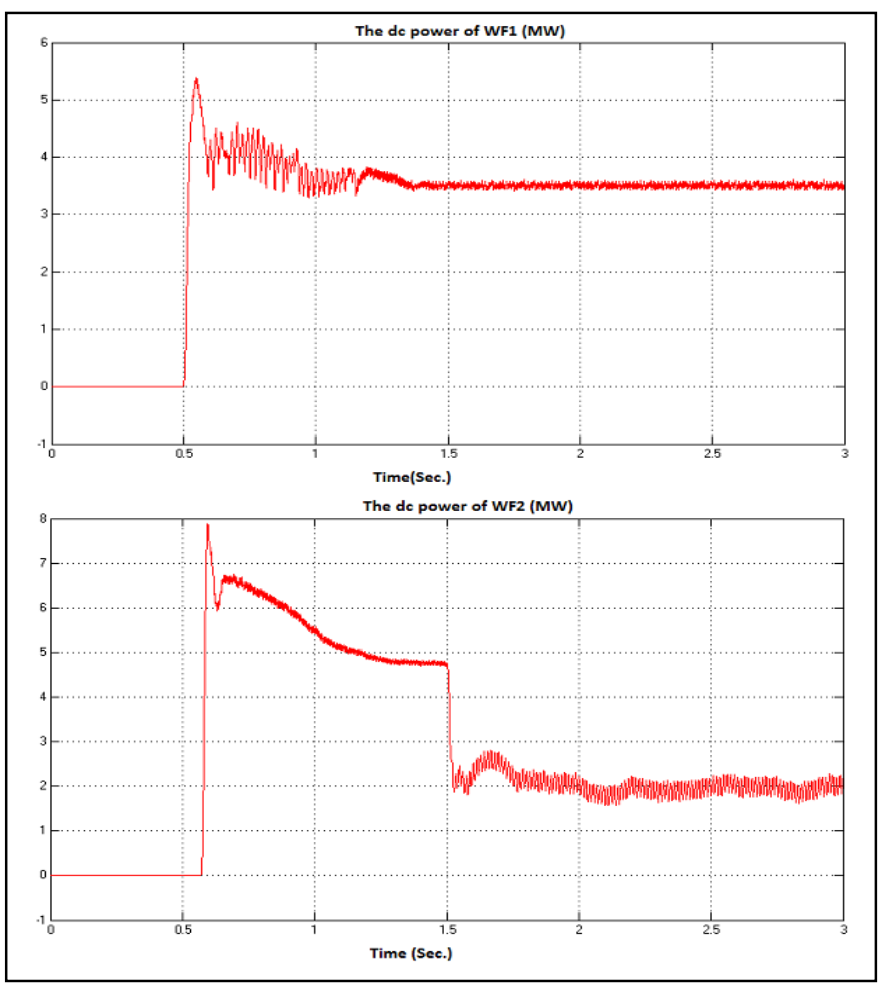

FIGURE XVII. THE DC POWER WAVEFORMS OF THE TWO WIND FARMS (MW).

\section{CONCLUSIONS}

In this paper, an MTDC system is implemented and simulated using MATLAB/SIMULINK software, to allow a typical four-terminals VSC-HVDC system to integrate large offshore wind farms with the grid. Hence, the considered 5.5 MW wind farms are capable of sharing the power with the two grids. The wind farm voltage source converters are controlled to successfully transfer the wind power to the two grids with acceptable THD for the grids. The DC voltage control loop which is a reference point for the current control loop of the WFS, its performance was once tested using a PID controller and then using Fuzzy Logic controller to compare the performance of both. The later shows better steady state and transient performance(less Vdc steady state oscillations, less overshoot, less settling time and faster response).

\section{REFERENCES}

[1] Michaal P. Bahrman, Jan.G and Bo.ANilsson, "Voltage source converter transmission technologies- The right fit for the application", [Power Engineering Society General Meeting,2003 IEEE].

[2] Feng wang, Lina Bertling, Tuan Le, Anders Mannikoff and Anders Bergman," An Overview Introduction of VSC-HVDC: State-of-art and Potential Applicationsin Electric Power Systems", BOLOGNA 2011.

[3] A Power Electronics Hand Book by M.H. Rashid, 5th edition, Academic Press 2001.

[4] Dr. John Fletcher and Jin Yang, "Introduction to Doubly-Fed Induction Generator for Wind Power Applications", University of Strathclyde, Glasgow UK 2002.

[5] Chen, Z.; Guerrero, J.M. \& Blaabjerg, F. (2009). A review of the state of the art of power electronics for wind turbines, IEEE Trans. Power Electron., Vol. 24, No. 8, August 2009, 1859-1875, ISSN 0885-8993.

[6] Akash A. Chandekar, R.K.Dhatrak and Dr.Z.J..Khan," Modelling and Simulation of diode clamp multilevel inverter fed three phase induction motor for cmv analysis using filter", International Journal of Advanced Research in Electrical, Electronics and Instrumentation Engineering, Vol. 2, Issue 8, August 2013.

[7] Power Electronics based AC drives by B.K.Bose, "SPWM", "Three Level Inverter",2011.

[8] Xiongguang Zhao, Qiang Song, Hong Rao, Xiaoqian Li, Xiaolin Li, and Wenhua Liu," Control of Multi-Terminal VSC-HVDC System to Integrate Large Offshore Wind Farms", International Journal of Computer and Electrical Engineering, Vol. 5, No. 2, April 2013.

[9] L. Xu, L.Z. Yao, and C. Sasse, "Grid Integration of Large DFIG based Wind Farms Using VSC Transmission", IEEE Trans. Power Systems, Vol. 22, No. 3, Aug. 2007, pp. 976-984.L. Xu, and B.R. Andersen, "Grid Connection of Large Offshore Wind Farms using

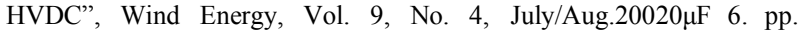
371382.

[10] Lie Xu,Barry W.Wiliams and Liangzhong Yao, "Multi-Terminal DC Transmission Systems for Connecting Large Offshore Wind Farms". 


\section{APPENDIX : SYSTEM RATINGS}

1. The parameters of the DFIG:

\begin{tabular}{|l|c|}
\hline The stator voltage & $4160 \mathrm{~V}(\mathrm{ph}-\mathrm{ph}$ RMS $)$ \\
\hline Frequency & $50 \mathrm{~Hz}$ \\
\hline VA rating ( Base) & $30 \mathrm{MVA}$ \\
\hline X/R ratio & 10 \\
\hline
\end{tabular}

2. The parameters of the three phase transformer (WFS1):

\begin{tabular}{|l|c|}
\hline The nominal power & $4 \mathrm{MVA}$ \\
\hline Frequency & $50 \mathrm{~Hz}$ \\
\hline Primary winding voltage $\mathrm{Yn}$ & $4160 \mathrm{~V}$ ( ph-ph RMS) \\
\hline Secondary winding voltage $\triangle$ & $22000 \mathrm{~V}$ \\
\hline Magnetizing resistance $\mathrm{R}_{\mathrm{m}}$ & 500 P.U \\
\hline Magnetizing reactance $\mathrm{X}_{\mathrm{m}}$ & 500 P.U \\
\hline
\end{tabular}

-The nominal power of the transformer of the WFS2 $=2 \mathrm{MVA}$

3. The parameters of the PID Controller (WFS):

\begin{tabular}{|l|c|}
\hline The proportional gain $\mathrm{K}_{\mathrm{p}}$ & 0.05 \\
\hline The integral gain $\mathrm{K}_{\mathrm{i}}$ & 1.6 \\
\hline The derivative gain $\mathrm{K}_{\mathrm{d}}$ & 0.001 \\
\hline
\end{tabular}

4. The parameters of the transformer (GS1):

\begin{tabular}{|l|c|}
\hline The nominal power & $4 \mathrm{MVA}$ \\
\hline Frequency & $50 \mathrm{~Hz}$ \\
\hline Primary winding voltage $\mathrm{Yn}$ & $45000 \mathrm{~V}(\mathrm{ph}-\mathrm{ph}$ RMS) \\
\hline Secondary winding voltage $\triangle$ & $22000 \mathrm{~V}$ \\
\hline Magnetizing resistance $\mathrm{R}_{\mathrm{m}}$ & 500 P.U \\
\hline Magnetizing reactance $\mathrm{X}_{\mathrm{m}}$ & 500 P.U \\
\hline
\end{tabular}

-The nominal power of the transformer of the GS2 $=2$ MVA.

5. The parameters of PI Controller (GS):

\begin{tabular}{|l|c|}
\hline The proportional gain $\mathrm{K}_{\mathrm{p}}$ & 3 \\
\hline The integral gain $\mathrm{K}_{\mathrm{i}}$ & 50 \\
\hline
\end{tabular}

6. The parameters of the transmission line:

\begin{tabular}{|l|c|}
\hline T.L of WF1 \& WF2 & $\mathrm{R}=0.1 \mathrm{~m} \Omega, \mathrm{L}=20 \mu \mathrm{H}$ \\
\hline Cable 1 parameters & $\mathrm{R}=10 \Omega, \mathrm{L}=0.03 \mathrm{H}$ \\
\hline Cable 2 parameters & $\mathrm{R}=0.001 \Omega, \mathrm{L}=0.00011$ \\
& $\mathrm{H}$ \\
\hline Cable 3 parameters & $\mathrm{R}=2.5 \Omega, \mathrm{L}=0.03 \mathrm{H}$ \\
\hline Cable 4 parameters & $\mathrm{R}=0.001 \Omega, \mathrm{L}=0.00011$ \\
& $\mathrm{H}=5 \Omega, \mathrm{L}=30 \mathrm{mH}$ \\
\hline T.L of GS1 \& GS2 & \\
& \\
\hline
\end{tabular}

